\title{
Numerical Analysis of Welding Residual Stress Relaxation in High-Strength Multilayer Weldment Under Fatigue Loads
}

\author{
HUI-JUN YI and YONG-JUN LEE \\ The primary purpose of this investigation was to study welding residual stress relaxation by \\ repeated loading. A coupling finite element analysis model for prediction of the welding residual \\ stress and the mechanical stress relaxation after external repeated loads was presented. The \\ accuracy of this model was verified through experiments. Also, it is found that the residual stress \\ of weldment is relaxed by external loads, and the greatest amount of relaxation was obtained by \\ early repeated loads. As the repetition count increased, the amount of relaxation became smaller \\ than the amount of relaxation in the early stage.
}

DOI: $10.1007 / \mathrm{s} 11663-017-0958-0$

(C) The Author(s) 2017. This article is an open access publication

\section{INTRODUCTION}

WELDING residual stress is caused by irregular temperature distribution during welding. Welding residual stress has a great impact on fatigue strength and on the fatigue life of welded structures, and the effects vary by whether the residual stress is tensile or compressive. ${ }^{[1]}$ Tensile residual stress is known to deteriorate the fatigue life of welded structures and cause stress corrosion cracking. For this reason, the residual stress in the weldments after welding of transportation equipment, ships, offshore plants, and steel bridge structures that receive continuous fatigue load is removed by using various methods. The methods for relaxing welding residual stress include postweld heat treatment, mechanical load application, vibration of the weldment, and peening or hammering of the parts with tensile residual stress to cause compressive residual stress on the surface. ${ }^{[2,3]}$ Among these methods, the mechanical stress relaxation (MSR) method applies an external load to the mechanical component with residual stress and makes the sum of the applied stress and the residual stress reach the yield stress of the material so that the residual stress will be relieved or redistributed. The welding residual stress is gradually relieved even under fatigue or vibration load as well as under a static load, and the relaxation level of the residual stress is known to be determined by the size and number of repeated loads. ${ }^{[4-6]}$

When assessing the fatigue life of welded structures, the effects of residual stress that affect the fatigue life of

HUI-JUN YI is with Hyundai-Rotem Company, Chang-won 51413, Korea. Contact e-mail: yi.h.jun@gmail.com YONG-JUN LEE is with the The 2nd Land System Team, Defense Agency for Technology and Quality, Changwon 51461, Korea.

Manuscript submitted August 13, 2016.

Article published online April 18, 2017. the structure must be considered. Especially for the design of steel bridge structures, the repeated load and vibration during use must be evaluated and their effect on the fatigue life must be predicted in the design.

Morrow et al. and Iida et al. studied the relaxation of welding residual stress and stress relaxation mechanisms under repeated load by experimental methods. They researched the effects of the number of repeated loads and the size of the external load on $700-\mathrm{MPa}$ grade carbon steels. ${ }^{[7-9]}$ Nevertheless, they used experimental methods with fatigue specimens and did not consider residual stress relief problems. Accordingly, in this study, a finite element analysis model for prediction of the welding residual stress for multipass weldments of $1100-\mathrm{MPa}$ high-strength steel and for prediction of the mechanical stress relaxation after external repeated loads was presented and verified through an experimental method. For this purpose, residual stress generated during the welding process was predicted through thermal-mechanical coupling analysis followed by mechanical analysis of residual stress relaxation by repeated loads.

\section{EXPERIMENTAL PROCEDURES}

For this test, mechanical stress relaxation of $1100 \mathrm{MPa}$ high-strength steel was studied, which is generally used in bridge devices for vehicle transportation, and the mechanical properties and chemical composition of the material are shown in Table I.

To prevent residual stress relaxation during the machining process, a special welding specimen was used as shown in Figure 1. The detailed welding conditions for the specimen production are shown in Table II. The specimens were welded with pulse GMAW to minimize the welding heat input, which occurs during welding. A K-type thermocouple was used to measure the heat generated during the heating and cooling cycles, and the position is shown in Figure 1. 
Table I. Chemical and Mechanical Properties of Base Metal

\begin{tabular}{lcccccccccccc}
\hline $\mathrm{C}$ & $\mathrm{Si}$ & $\mathrm{Mn}$ & $\mathrm{Ni}$ & $\mathrm{Cr}$ & $\mathrm{Mo}$ & $\mathrm{Cu}$ & $\mathrm{Nb}$ & $\mathrm{Al}$ & $\mathrm{V}$ & $\mathrm{TS}(\mathrm{MPa})$ & $\mathrm{YS}(\mathrm{MPa})$ & $\mathrm{EI}(\mathrm{Pct})$ \\
\hline 0.17 & 0.24 & 0.84 & 2.00 & 0.56 & 0.60 & 0.02 & 0.02 & 0.057 & 0.028 & 1250.0 & 1100.0 & 8.0 \\
\hline
\end{tabular}

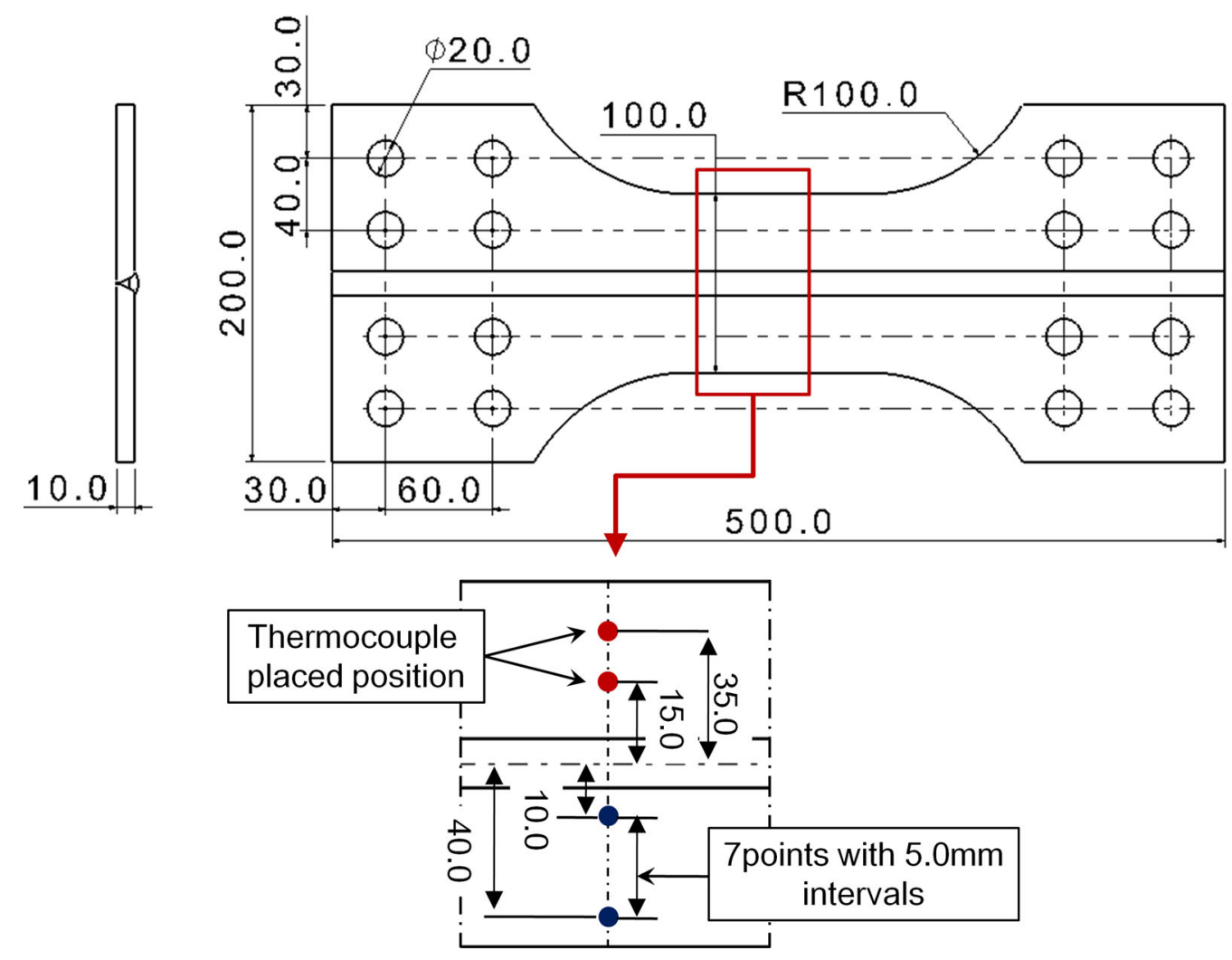

Fig. 1-Illustration of welding specimen and position of thermocouple and XRD measuring points.

Table II. Welding Parameters

\begin{tabular}{lcccc}
\hline Numbers of Passes & Current (A) & Voltage (V) & Welding Speed (cm/min) & Remarks \\
\hline 1 & 210.0 & 25.1 & 35.0 & pulse \\
2 & 215.0 & 29.0 & 35.0 & pulse \\
\hline
\end{tabular}

A universal fatigue testing machine from MTS with the capacity of 100 tons was used to apply the repeated loads, and a strain gage was attached to measure the strain history of the specimens during the test as shown in Figure 2. A fatigue test with constant load amplitude was conducted under the conditions for repeated loads of 0.1 load ratio and $5-\mathrm{Hz}$ load frequency. Figure 3 shows the $\mathrm{S}-\mathrm{N}$ line diagrams for the materials and weldments. To check the degree of residual stress relaxation by the size of the repeated load, one load condition was selected for each high-load, low-frequency area (700 $\mathrm{MPa}$ ) and low-load, high-frequency area $(300 \mathrm{MPa})$ on the $\mathrm{S}-\mathrm{N}$ line diagrams.
To check the degree of residual stress relaxation by the number of repeated external loads, the repeated load counts of $1 \times 10,2 \times 10^{3}$, and $5 \times 10^{4}$ cycles were applied at $\Delta \sigma=300 \mathrm{MPa}$ and $1 \times 10$ and $2 \times 10^{3}$ cycles at $\Delta \sigma=700 \mathrm{MPa}$.

The degree of the residual stress relaxation by the repetition cycle count under constant fatigue load was measured with a portable X-ray diffractometer (XRD) device, and the measurement positions are shown in Figure 1. For measuring residual stress, the specimen surface was exposed for 10 seconds with two angles of 30 and -30 deg. A standard $\sin ^{2} \psi$ technique was employed. 


\section{FINITE ELEMENT MODEL AND SIMULATION}

\section{A. Welding Process}

1. Heat input model

A volumetric heat source with a double-ellipsoidal distribution model is applied as the heat from welding and is expressed by the following equations. ${ }^{[10]}$

For the front heat source:

$$
Q\left(x^{\prime}, y^{\prime} z^{\prime}, t\right)=\frac{6 \sqrt{3} f_{\mathrm{f}} Q_{\mathrm{w}}}{a_{1} b c \pi \sqrt{\pi}} e^{-3 x^{\prime 2} / a_{1}^{2}} e^{-3 y^{\prime 2} / b^{2}} e^{-3 z^{\prime 2} / c^{2}}
$$

For the rear heat source:

$$
Q\left(x^{\prime}, y^{\prime} z^{\prime}, t\right)=\frac{6 \sqrt{3} f_{\mathrm{r}} Q_{\mathrm{w}}}{a_{2} b c \pi \sqrt{\pi}} e^{-3 x^{\prime 2} / a_{2}^{2}} e^{-3 y^{\prime 2} / b^{2}} e^{-3 z^{\prime 2} / c^{2}}
$$

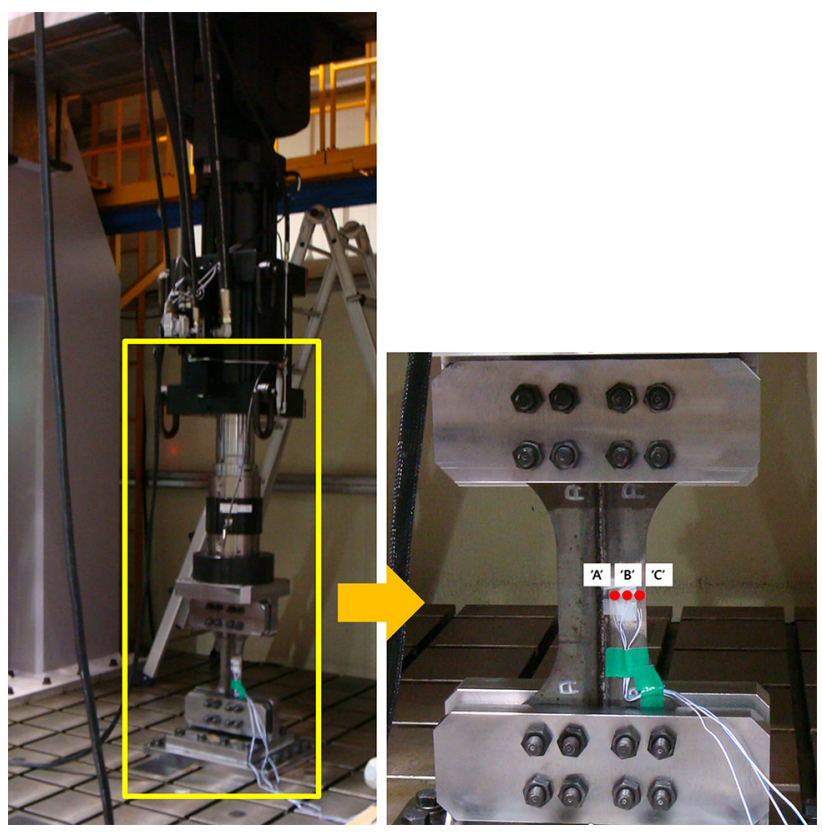

Fig. 2-Illustration of fatigue test and position of strain gage.

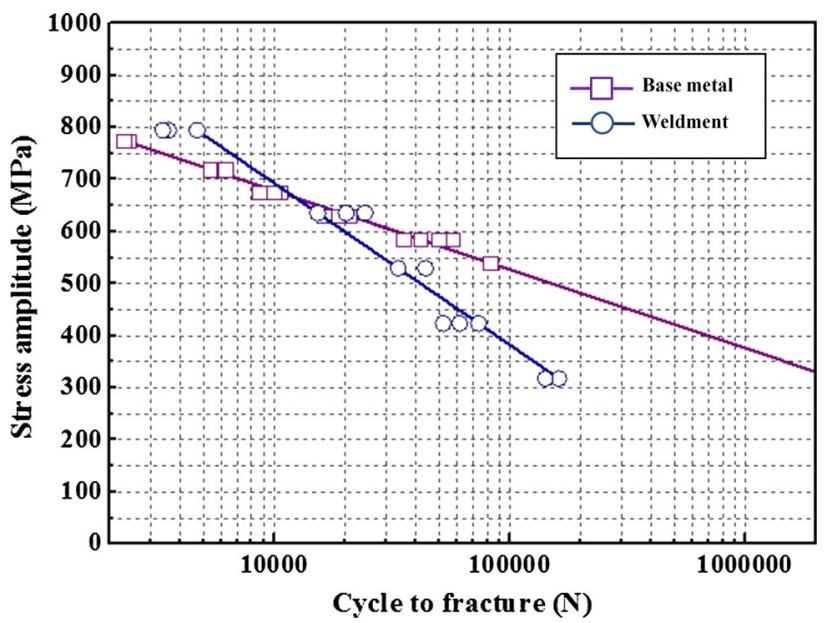

Fig. 3-S-N curve of base metal and weldment. $f_{\mathrm{f}}$ is the parameter of front heat deposition, and $f_{\mathrm{r}}$ is the parameter of rear heat deposition parts. The temperature distribution in front and rear parts is expressed by the following equation. $x^{\prime}, y^{\prime}$, and $z^{\prime}$ are the local coordinates of the heat model:

$$
f_{\mathrm{f}}=\frac{2}{\left(1+c_{2} / c_{1}\right)}, f_{\mathrm{r}}=\frac{2}{\left(1+c_{1} / c_{2}\right)}, f_{\mathrm{f}}+f_{\mathrm{r}}=2
$$

The parameters $a, b, c_{1}$, and $c_{2}$ are very close to the welding heat source characteristics, ${ }^{[10,11]}$ and those parameters used in this study are summarized in Table III. $Q_{\mathrm{w}}$ is the power of welding heat source calculated from the welding current, voltage, and arc efficiency ( 0.9 in this study). ${ }^{4]}$ The welding heat source power is determined using the following equation (Table IV):

$$
Q_{\mathrm{w}}=\eta E I
$$

As shown in Figure 4, a 20 pet ramp ratio is used to increase the convergence rate at the start and end of the welding FEA. ${ }^{[12]}$

\section{Heat transfer analysis}

During welding, the governing equation for transient nonlinear heat transfer is:

$$
\frac{\partial}{\partial x}\left(\lambda \frac{\partial T}{\partial x}\right)+\frac{\partial}{\partial y}\left(\lambda \frac{\partial T}{\partial y}\right)+\frac{\partial}{\partial z}\left(\lambda \frac{\partial T}{\partial z}\right)+Q=\rho c \frac{\partial T}{\partial t}
$$

Heat losses due to convection and radiation are considered in the finite element models. All surfaces of the model are assumed to lose heat by convection to the

\section{Table III. Nomenclature of Double Ellipsoidal Equation}

\begin{tabular}{llc}
\hline Symbol & \multicolumn{1}{c}{ Name (Meaning) } & SI Units \\
\hline$a$ & width of heat source, along $x$ axis & $\mathrm{mm}$ \\
$b$ & depth of heat source, along $x$ axis & $\mathrm{mm}$ \\
$c_{1}$ & length of frontal ellipsoidal & $\mathrm{mm}$ \\
$c_{2}$ & $\begin{array}{l}\text { length of rear ellipsoidal } \\
\text { fraction of heat deposited in }\end{array}$ & $\mathrm{mm}$ \\
$f_{\mathrm{f}}$ & $\quad$ frontal ellipsoidal & \\
& fraction of heat deposited in rear & - \\
$f_{\mathrm{r}}$ & $\quad$ ellipsoidal & $\mathrm{W}$ \\
$Q_{\mathrm{w}}$ & total arc heat & $\mathrm{A}$ \\
$I$ & welding current & $\mathrm{V}$ \\
$E$ & welding voltage & \\
$x^{\prime}, y^{\prime}, z^{\prime}$ & coordinate &
\end{tabular}

Table IV. Welding Heat Source Parameters

\begin{tabular}{lc}
\hline Parameter & Value $(\mathrm{mm})$ \\
\hline$a$ & 10.0 \\
$b$ & 5.0 \\
$c_{1}$ & 20.0 \\
$c_{2}$ & 2.0 \\
\hline
\end{tabular}




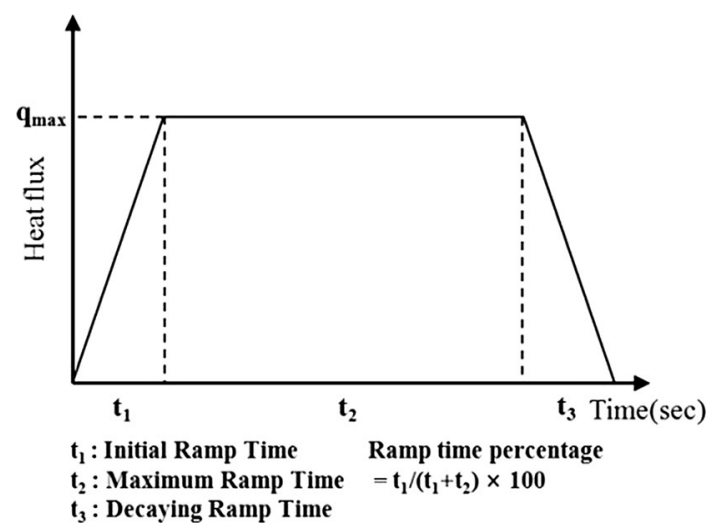

Fig. 4-Description of 20 pct ramp heat input function.

surrounding air. Heat loss due to convection is accounted for using Newton's law, ${ }^{[6,12]}$ and a temperature-dependent film coefficient is adopted. The ambient temperature is assumed to be $298 \mathrm{~K}\left(25^{\circ} \mathrm{C}\right)$ :

$$
q_{\mathrm{r}}=-h_{\mathrm{c}}\left(T_{\mathrm{S}}-T_{0}\right)
$$

Here, $h_{\mathrm{c}}$ is the heat transfer coefficient, $T_{\mathrm{s}}$ is the surface temperature, and $T_{0}$ is the ambient temperature. The heat loss due to radiation is modeled using the Stefan-Boltzmann law: ${ }^{[13]}$

$$
q_{\mathrm{r}}=-\varepsilon \sigma\left[\left(T_{S}\right)^{4}-\left(T_{0}\right)^{4}\right]
$$

Here, $\varepsilon$ is the emissivity and is assumed to be $0.2 \cdot{ }^{[14]} \sigma$ is the Stefan-Boltzmann constant. Thermal conductivity and specific heat are the function of the temperature-dependent thermal properties used in this study. To make the correct moving weld heat source, element activation and deactivation methods are used for the weld deposition model. Each weld bead geometry data and welding parameters are taken from experiment data. The value of the latent heat is $270 \mathrm{~J} / \mathrm{g}$. The liquidus temperature $T_{\mathrm{L}}$ and the solidus temperature $T_{\mathrm{S}}$ are assumed to be $1773 \mathrm{~K}$ and $1723 \mathrm{~K}\left(1500{ }^{\circ} \mathrm{C}\right.$ and $\left.1450{ }^{\circ} \mathrm{C}\right)$, respectively. ${ }^{[14]}$

\section{Mechanical analysis}

Elasticity modulus, yield stress, and strain are the function of temperature-dependent properties, and they are used for mechanical analysis. The steel phase transformation effect on welding deformation and residual stress are taken into account with three components as follows: ${ }^{[15]}$

$$
\varepsilon^{\text {total }}=\varepsilon^{\mathrm{e}}+\varepsilon^{\mathrm{p}}+\varepsilon^{\text {th }}
$$

Here, $\varepsilon^{\mathrm{e}}, \varepsilon^{\mathrm{p}}$, and $\varepsilon^{\text {th }}$ are the elastic, plastic, and thermal strains, respectively. Hooke's law is used for the model of the elastic strain with temperature-dependent elastic modulus. For the model of plastic strain, temperature-dependent yield stress is employed. The temperature-dependent properties are described in Figure 5. Work hardening is not taken into account in the present study.

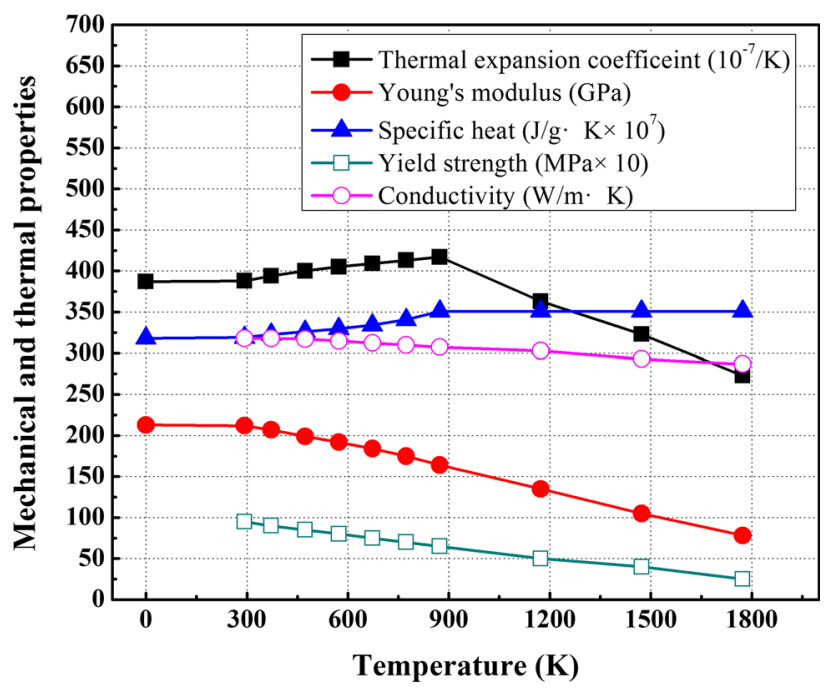

Fig. 5-Temperature-dependent mechanical and thermal properties.

\section{B. Residual Stress Relaxation Model by Load Cycle Count}

\section{Mechanical stress relaxation mechanism}

When an external load is applied to a member with residual stress, the residual stress is relaxed if the sum of the applied stress by an external load and the residual stress exceeds the yield stress of the material. Figure 6(a) shows a schematic illustration where the external load $P$ is applied to a cylinder for which the compressive residual stress $\sigma_{\mathrm{rs}}(\mathrm{s})$ is applied to the surface and the tensile residual stress $\sigma_{\text {re }}(i)$ is applied to the inside. Assuming that there is no work hardening, when the tensile load $P$ is applied, the surface stress $\sigma_{\mathrm{s}}$, the central stress $\sigma_{\mathrm{i}}$, and the combined stress $\sigma_{\mathrm{t}}$ increase linearly together with the tensile strain $\varepsilon . \sigma_{\mathrm{i}}$ reaches the yield point of the material with a strain smaller than the surface, and $\sigma_{\mathrm{t}}$ makes a plastic line diagram with continuous load after reaching the tensile combined yield point $\sigma_{\mathrm{y}}(t)$ of the center and surface. Therefore, when a tensile stress greater than the combined yield point is applied, a stress relaxation effect can be obtained from the center and surface. The residual stress relaxation due to mechanical loads is only possible within the pro-hatched area of Figure 6(b). The residual stress relaxation mechanism by fatigue load can be represented on a $\Delta \sigma-N$ line diagram as shown in Figure 6. In the high-load, low-frequency area, residual stresses relaxation occurs when the sum of the applied stress and the residual stress exceeds the yield stress, as with the model in Figure 7. For residual stress relaxation in the low-load, high-frequency areas, $\Delta \sigma$ and the cycle count $N$ are important variables. In particular, residual stress relaxation is large in the first or several fatigue cycles, and an increase of the cycle count brings about exponential or algebraic relaxation. ${ }^{[16]}$ The degree of residual stress relaxation is determined by the size of the applied load. Furthermore, residual stress is known to be relaxed in the fatigue load area where the fatigue load is very low. Major relaxation mechanisms make 


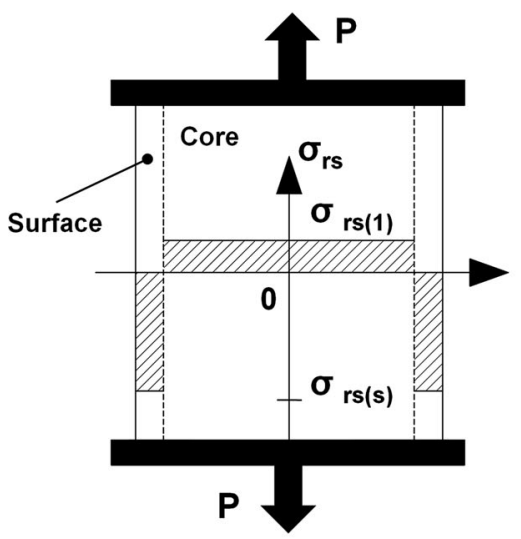

(a)

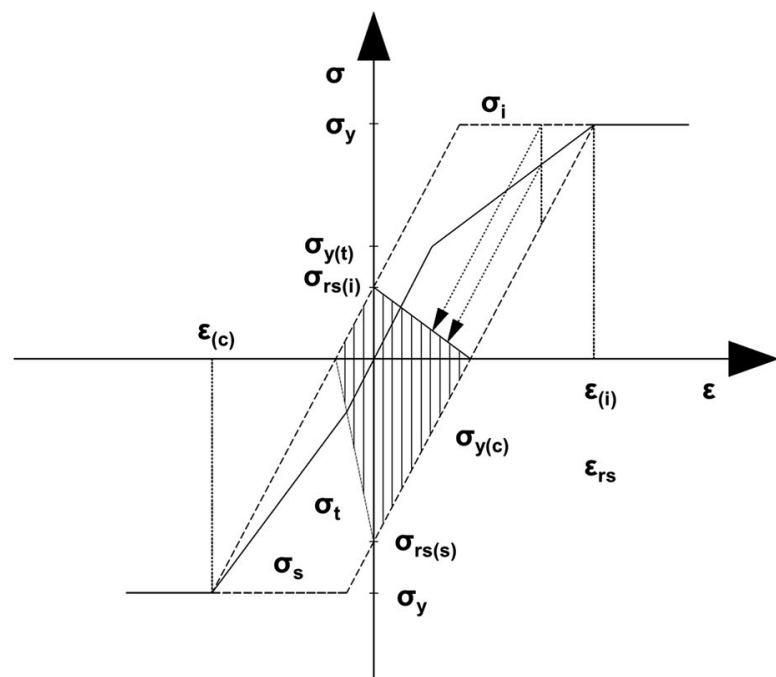

(b)

Fig. 6-Simple model for residual stress relaxation due to uniaxial loading: $(a)$ distribution of loading residual stress and $(b)$ model for residual stress relaxation.

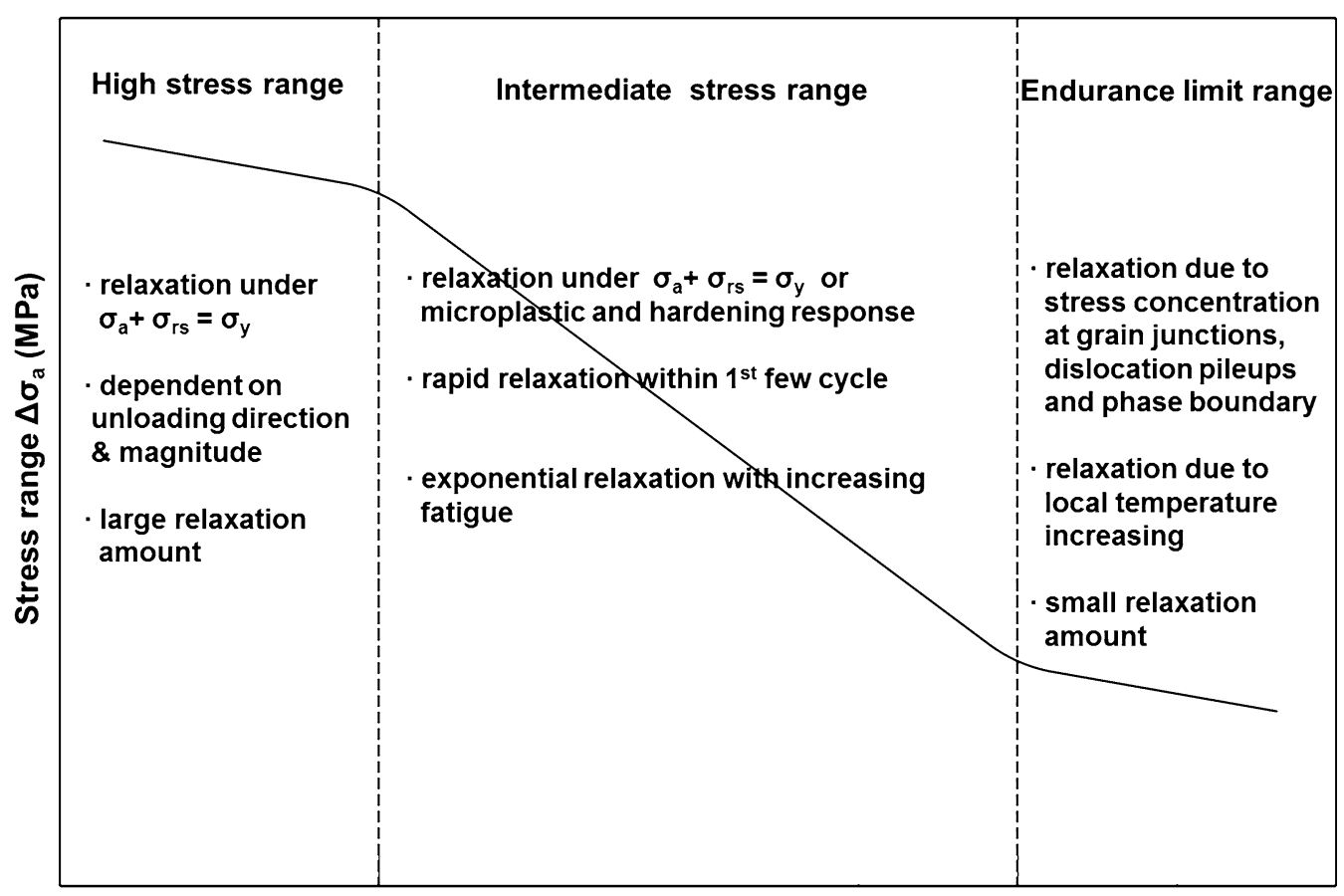

Cycle N

Fig. 7-Mechanism of residual stress relaxation according to amplitude of fatigue stress.

local temperatures rise by high cycles, and stress concentrations that occur at the grain diameter crossing point, potential contact, and phase boundary, which generate local plastic flow, thereby cause residual stress relaxation. At this load level, residual stress relaxation has a large time dependence and is characterized by a very small relaxation amount as the residual stress relaxation is caused by local micro plastic flows. ${ }^{[5,16]}$
2. Residual stress relaxation model

Han et al. ${ }^{[16]}$ proposed the following relational expression regarding the load repetition count under constant amplitude load and the relaxation of welding residual stress. Under the assumption that the major factors influencing the residual stress relaxation of welded structures under fatigue load are stress range and load count, an experiment of residual stress 
relaxation characteristics was conducted with the knowledge that the greatest relaxation occurs at the first or several number of load repetitions and the relaxation gradually decreases in accordance with the repeated load count after that was expressed as a power function as shown;

$$
\left(\sigma_{\text {res }}\right)_{\text {relax }} /\left(\sigma_{\text {res }}\right)_{1 \text { cycle }}=N^{-K}
$$

where $\left(\sigma_{\text {res }}\right)_{1 \text { cycle }}$ refers to the residual stress after relaxation after the first repetition count, $N$ the load repetition count, and $K$ the relaxation index. The residual stress value after welding was divided by the result after the first load cycle. $\left(\sigma_{\text {res }}\right)_{1 \text { cycle }}$ can be represented as a percentage of the initial residual stress $\left(\sigma_{\text {res }}\right)_{\text {ini }}$ through a static load test. If the sum of $\left(\sigma_{\text {res }}\right)_{\text {ini }}$ and the external load by the applied stress exceeds the yield stress of the material, the amount of the residual stress relaxation is determined by the degree of the excess. In other words, as $\left[\left(\sigma_{\text {res }}\right)_{\text {ini }}+\sigma_{\text {app }}\right] / \sigma_{\text {y }}$ increases, $\left[\left(\sigma_{\text {res }}\right)_{1 \text { cylce }} /\left(\sigma_{\text {res }}\right)_{\text {ini }}\right]$ decreases linearly, which can be expressed as follows:

$$
\begin{gathered}
{\left[\left(\sigma_{\text {res }}\right)_{\text {ini }}+\sigma_{\text {app }}\right] / \sigma_{\mathrm{y}}<1:\left(\sigma_{\text {res }}\right)_{1 \text { cycle }} /\left(\sigma_{\text {res }}\right)_{\text {ini }}=1} \\
{\left[\left(\sigma_{\text {res }}\right)_{\text {ini }}+\sigma_{\text {app }}\right] / \sigma_{\mathrm{y}} \geq 1:} \\
\left(\sigma_{\text {res }}\right)_{1 \text { cycle }} /\left(\sigma_{\text {res }}\right)_{\text {ini }}=-1.6\left[\left\{\left(\sigma_{\text {res }}\right)_{\text {ini }}+\sigma_{\text {app }}\right\} / \sigma_{\mathrm{y}}+2.6\right.
\end{gathered}
$$

This is the result of measuring the size of residual stress relaxation while applying a fatigue load to determine the relaxation index $K .\left(\sigma_{\text {res }}\right)_{\text {relax }} /\left(\sigma_{\text {res }}\right)_{1 \text { cycle }}$ showed a gradually decreasing trend until the load repetition count $N$ reached $10^{7}$ cycles and $K$ was determined to be 0.0045 . When this value is substituted in Eqs. [8] through [10], the size of residual stress relaxed under the fatigue load $\left(\sigma_{\text {res }}\right)_{\text {relax }}$ can be expressed as the term $\left[\left(\sigma_{\text {res }}\right)_{\text {ini }}+\sigma_{\text {app }}\right] / \sigma_{\mathrm{y}}$ :

$$
\left[\left(\sigma_{\text {res }}\right)_{\text {ini }}+\sigma_{\text {app }}\right] / \sigma_{\mathrm{y}}<1:\left(\sigma_{\text {res }}\right)_{\text {relax }}=\left(\sigma_{\text {res }}\right)_{\text {ini }} \cdot N^{-0.0045}
$$

$$
\begin{aligned}
& {\left[\left(\sigma_{\text {res }}\right)_{\text {ini }}+\sigma_{\text {app }}\right] / \sigma_{\mathrm{y}} \geq 1:\left(\sigma_{\text {res }}\right)_{\text {relax }}} \\
& =\left(\sigma_{\text {res }}\right)_{\text {ini }} \cdot\left(-1.6\left[\left\{\left(\sigma_{\text {res }}\right)_{\text {ini }}+\sigma_{\text {app }}\right\} / \sigma_{\mathrm{y}}+2.6\right) \cdot N^{-0.0045}\right.
\end{aligned}
$$

\section{Simulations}

In this study, a 3D finite element model was developed to simulate welding residual stress. The numbers of elements and nodes in each model are 12,324 and 15,114 , respectively. A coupled thermomechanical analysis is used to calculate the welding residual stress induced by the multi-ass welding process. The shape of the groove and the weld passes of each model are shown in Figure 8.

To verify the relaxation of residual stress of the weldments by repeated fatigue loads after the welding

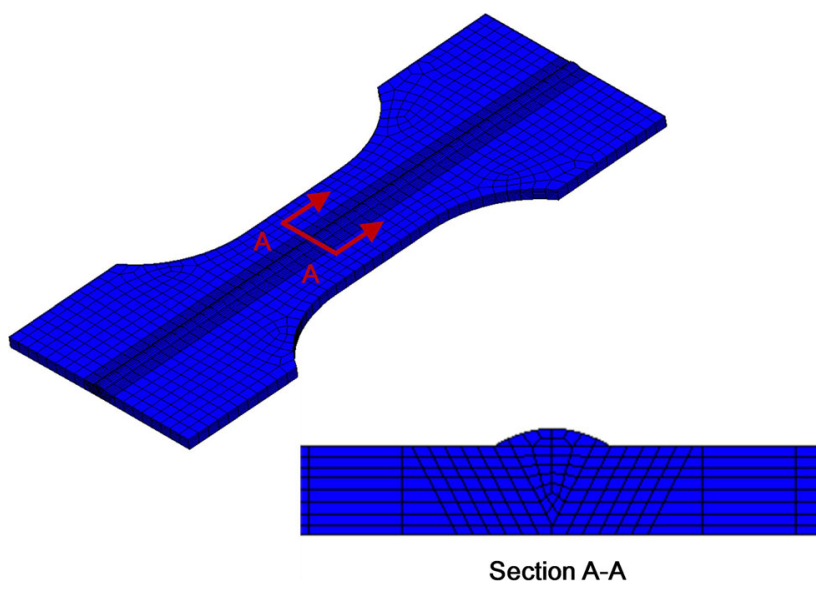

Fig. 8-Finite element analysis model of welding and MSR process.

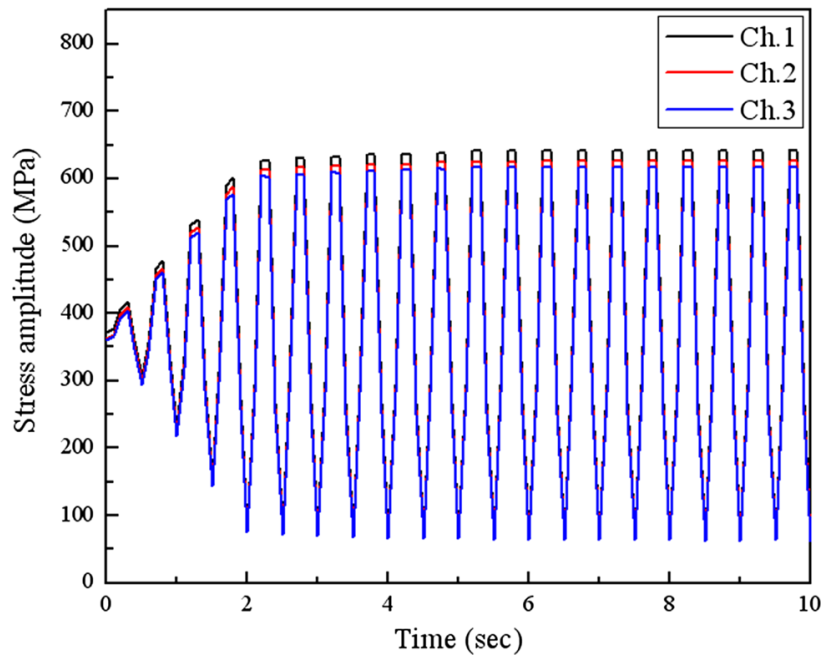

Fig. 9-Loading input of MSR experiment.

process analysis, the load values assigned by the MTS system were given as load over time to the finite element analysis model, as shown in Figure 9. Mechanical analysis was used, and to minimize errors that may occur in the early stage of analysis, a strain gage was attached as shown in Figure 2, and the repeated load condition was applied after comparing the stress response results by load with the analysis results. The finite element analysis was performed using MSC.Marc.

\section{RESULTS AND DISCUSSION}

The analysis results were presented as shown in Figure 10. The temperature histories of welding are shown in Figure 11. The results showed that temperature distributions were well matched with the experimental measurements. The residual stress of the weldments was measured with XRD, and these measurements were compared with the analysis results in Figure 12. As a result of the comparison, the measurement results agreed well with the prediction results of the finite element analysis. 

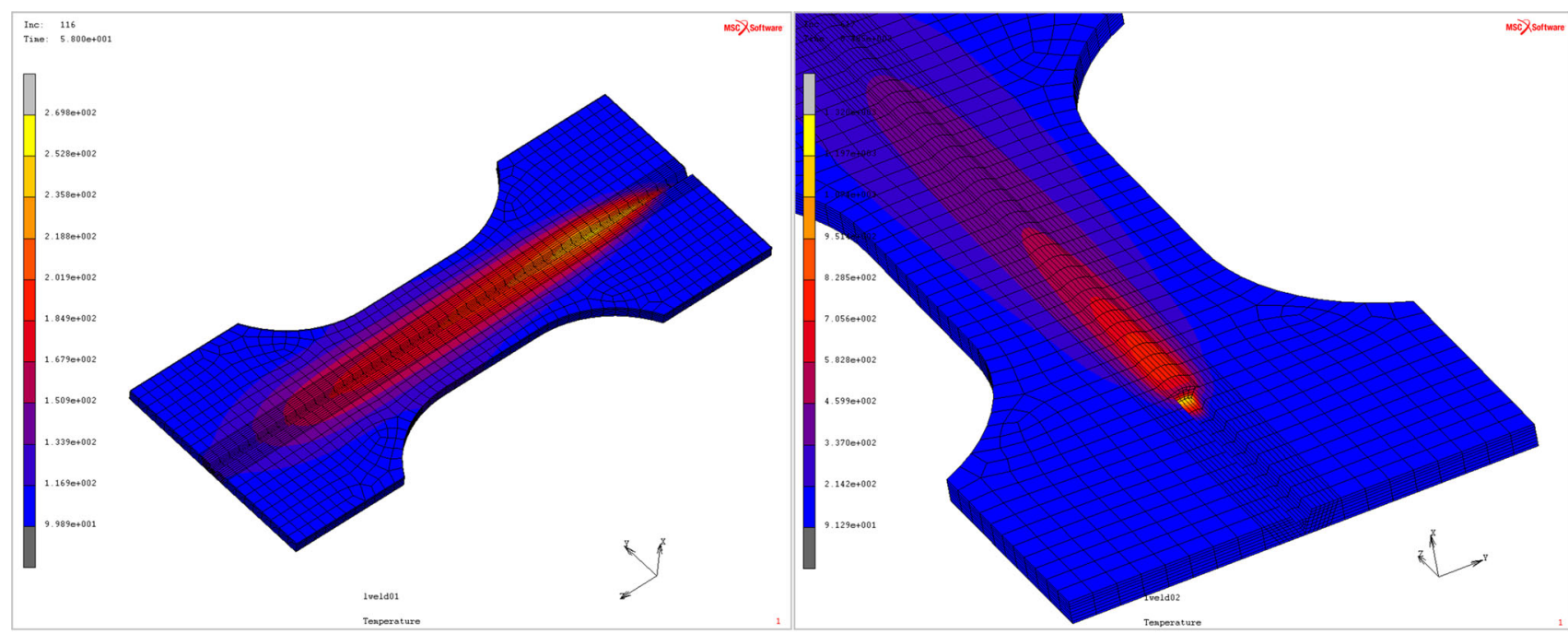

(a)
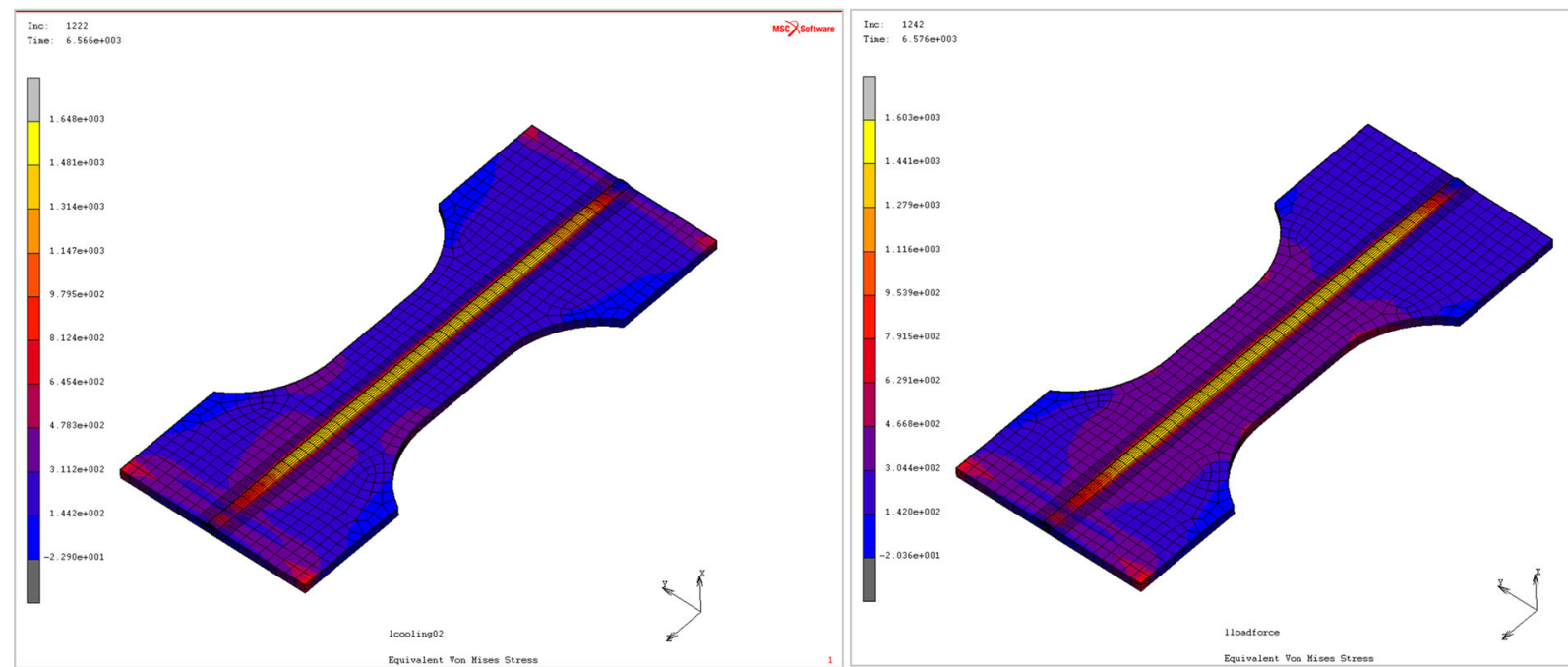

(b)

Fig. 10-Results of finite element analysis prediction: $(a)$ welding analysis results and $(b)$ mechanical loading analysis results.

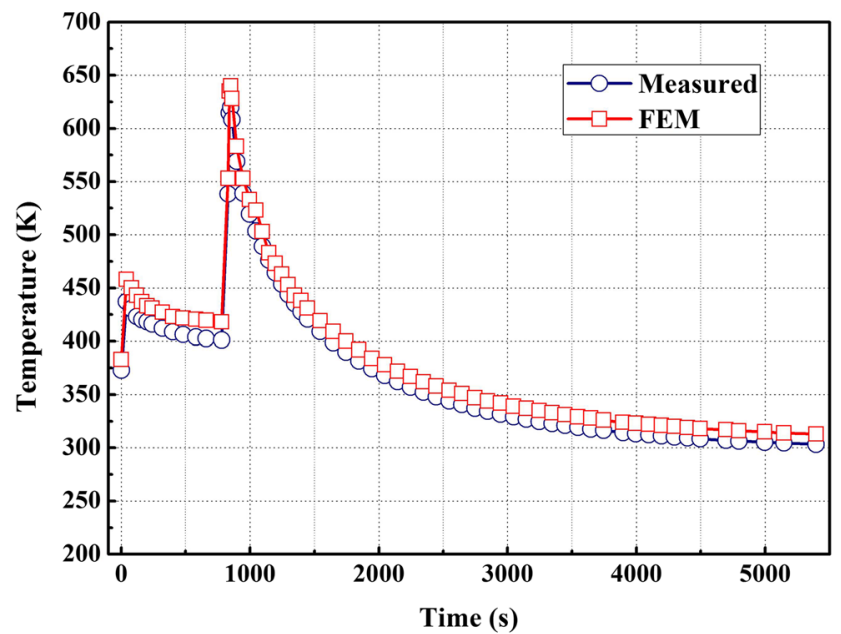

(a)

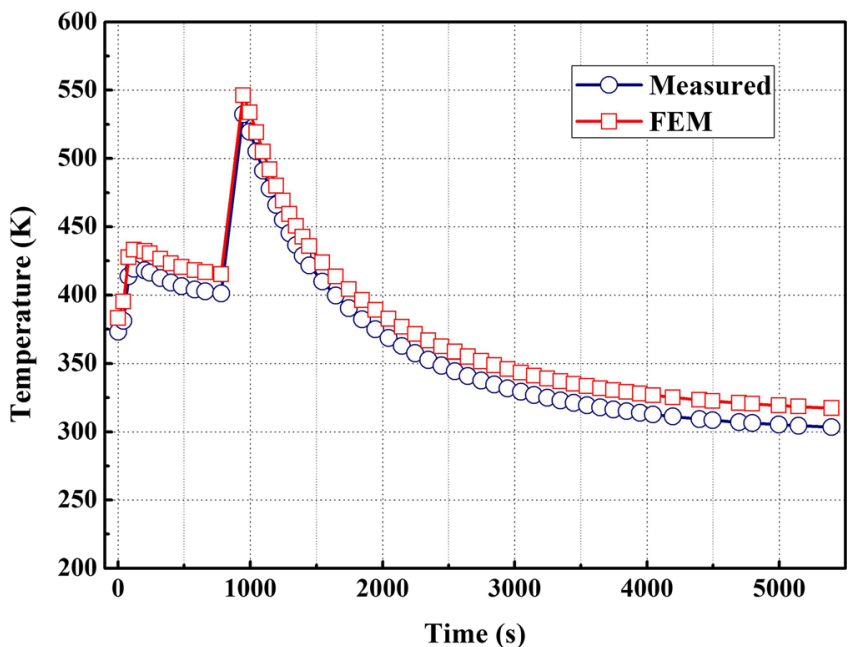

(b)

Fig. 11-Results of comparing temperature histories: (a) $15 \mathrm{~mm}$ from the center and (b) $35 \mathrm{~mm}$ from the center. 


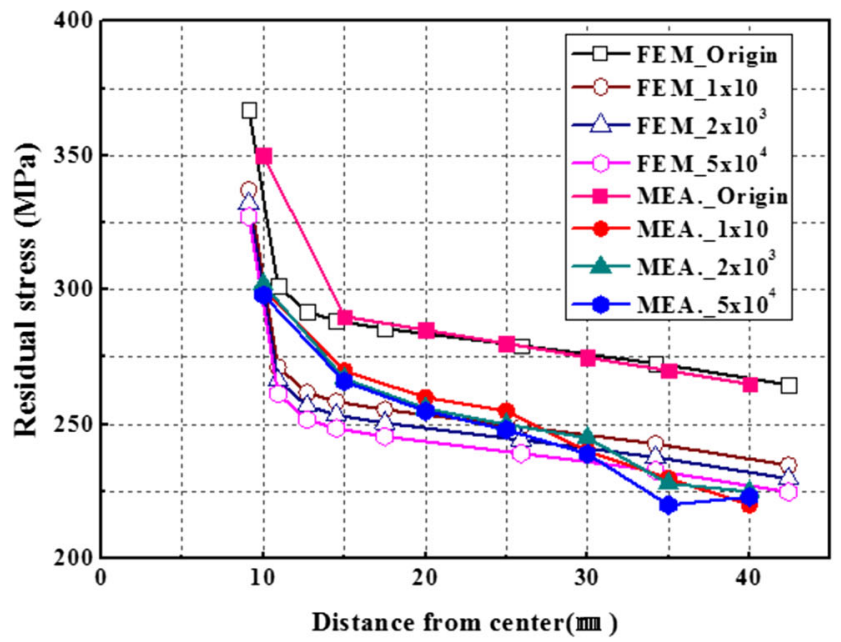

(a)

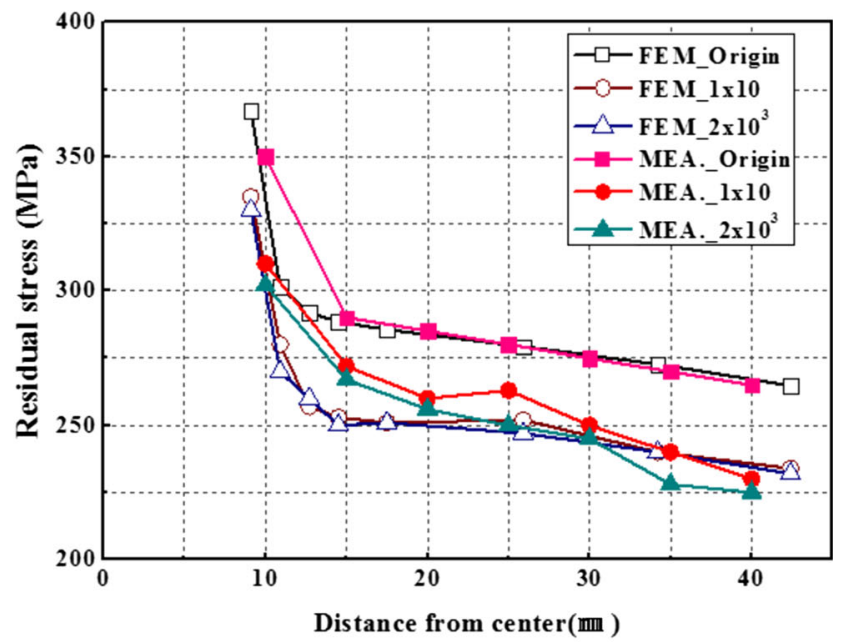

(b)

Fig. 12-MSR results; comparing between XRD measurement and FEM prediction: (a) 300-MPa condition and (b) 700-MPa condition.

Figure 12 shows the changes of residual stress according to load repetition count at the stress levels of $\Delta \sigma=300$ and $700 \mathrm{MPa}$ by comparing the XRD measurement values and the finite element analysis. In every case, the residual stress of weldments was relaxed greatly at $1 \times 10$ cycles, and the increased repetition count did not have a significant effect on the amount of relaxation of the residual stress.

The residual stress does not exist as a constant size in the weldments, but compressive and tensile residual stresses coexist while maintaining equilibrium. If a load of a certain size is applied to the outside, a relaxation effect appears when the sum of the applied stress by the external load and the residual stress reaches the yield stress of the material. At this moment, the local plastic strain is generated as a dislocation slip inside the grains and the residual stress is relaxed as the residual stress remaining as elastic strain is converted into plastic strain. The results of this study found the greatest residual stress relaxation effect at the $1 \times 10$ cycles, and after which, no great effects were found regardless of the number of cycles. This suggests that when the potential moves inside the grains by plastic strain through the slip system, but due to the limitations of this slip system and the potential density, no effects of residual stress relaxation can be obtained from $1 \times 10$ cycles or higher loads.

\section{CONCLUSION}

In this study, a model for predicting the accurate fatigue life of high-tension steel weldments used in steel bridge structures that are subjected to repeated loads was developed considering the effects of mechanical residual stress relaxation. For this purpose, a thermal-mechanical coupling analysis model for predicting the residual stress of weldments and a mechanical analysis model for the relaxation of mechanical residual stress were presented. The accuracy of these models was verified through experiments.
Based on the experimental measurements and the simulated studies, the results can be summarized as follows:

1. The residual stress of weldments is relaxed by external loads, and the greatest amount of relaxation was obtained by early repeated loads regardless of the load size. As the repetition count increased, the amount of relaxation became smaller than the amount of relaxation in the early stage.

2. The residual stress relaxation model proposed in this study is expected to be applied for prediction of the fatigue life of actual welded structures.

\section{OPEN ACCESS}

This article is distributed under the terms of the Creative Commons Attribution 4.0 International License (http://creativecommons.org/licenses/by/4.0/), which permits unrestricted use, distribution, and reproduction in any medium, provided you give appropriate credit to the original author(s) and the source, provide a link to the Creative Commons license, and indicate if changes were made.

\section{REFERENCES}

1. K. Masubuchi: Analysis of Welded Structures, Pergamon Press, Oxford, 1980.

2. S.J. Madox: Fatigue Strength of Welded Structures, 2nd ed., Abington Publishing, Cambridge, 1991.

3. J.F. Throop, J.H. Underwood, and G.S. Leger: Thermal Relaxation in Autofrettaged Cylinders, Residual Stress and Stress Relaxation, Plenum Press, New York, 1982.

4. M.R. James: Relaxation of Residual Stress an Overview, Advance in Surface Treatment, Technology-Applications-Effects, Pergamon Books Ltd., Oxford, 1997.

5. Y.W. Kim and H.J. Kim: J. Weld. Join., 1987, vols. 5-2, pp. 1-8.

6. H. Holzapfel, V. Schulze, O. Vohringer, and E. Macherauch: Mater. Sci. Eng. A, 1998, vol. 248, pp. 9-18. 
7. J.D. Morrow, A.S. Ross, and G.M. Sinclair: SAE Trans., 1960, vol. 68 , pp. $40-48$.

8. E.J. Pattinson and D.S. Dugdole: Metall. Trans A, 1982, vol. 66, pp. $228-30$

9. K. Iida, S. Yamamoto, and M. Takanashi: Weld. World, 1997, vol. 39 , pp. 138-44.

10. J. Goldak, A. Chakravarti, and A.M. Bibby: Metall. Trans. B, 1984, vol. 15B, pp. 299-305.

11. N. Christensen, V.L. Davis, and K. Gjermundsen: Br. Weld. J., 1965, pp. 54-75.
12. Y.L. Shim and S.G. Lee: J. Weld. Join., 1993, vol. 11, pp. 110-23.

13. K. Ogawa, D. Deng, S. Kiyoshima, N. Yanagida, and K. Saito: Comput. Mater. Sci., 2009, vol. 45, pp. 1031-42.

14. P. Michaleris and A. DeBiccari: Weld. Res. Suppl., 1997, pp. 172-81.

15. D. Radaj: Heat Effects of Welding, Temperature Filed, Residual Stress, Distortion, Springer, New York, 1992.

16. S.H. Han and B.C. Shin: J. Weld. Join., 2002, vol. 23, pp. 84-90. 